\title{
Surface structures, haemagglutination and cell surface hydrophobicity of Bacteroides fragilis strains
}

\author{
Petra C. F. Oyston and Pauline S. Handley* \\ Cell and Structural Biology, Stopford Building, University of Manchester, Oxford Road, Manchester M13 9PT, UK
}

(Received 2 November 1989; revised 5 January 1990; accepted 30 January 1990)

\begin{abstract}
Nineteen strains of Bacteroides fragilis were examined by negative staining for surface structures. One strain (ATCC 23745) possessed peritrichous fibrils, 16 strains carried peritrichous fimbriae and two strains carried no surface structures. The fimbriae had a diameter of $2 \cdot 1 \pm 0 \cdot 25 \mathrm{~nm}$ and appeared to be 'curly'. Only a small proportion ( 4 to $41 \%$, depending on the strain) of cells in a population carried fimbriae or fibrils. Strain A312 showed phase variation of fimbriae as expression of fimbriae was repressed at $20^{\circ} \mathrm{C}$ and in early exponential phase at $37^{\circ} \mathrm{C}$. The fibrils on strain ATCC 23745 did not exhibit phase variation in response to changes in incubation temperature, growth phase or growth in two different media. Capsules were demonstrated by the Indian ink method on 18 of the 19 strains, varying in size from strain to strain and within the same population. Cultures often contained both capsulate and noncapsulate cells. All strains possessed an electron dense ruthenium red staining layer between 7.9 and $23.9 \mathrm{~nm}$ in width attached to the outer membrane. Cell surface hydrophobicity quantified by the hexadecane partition assay gave low values ranging from 6.6 to $52.1 \%$. Only a few strains were able to haemagglutinate and these were only weakly active. There was no correlation between cell surface hydrophobicity, haemagglutinating activity and surface structures.
\end{abstract}

\section{Introduction}

Bacteroides fragilis is the most common Gram-negative anaerobe isolated from clinical infections (Onderdonk $e t$ al., 1977) such as bacteraemia, wound, intra-abdominal and urogenital infections (Lindberg et al., 1979). Adhesion to epithelial surfaces is considered to be a prerequisite for pathogenicity for most bacteria, but the cell surface components that mediate in adhesion of $B$. fragilis have not been unequivocally identified.

Fimbriae are proteinaceous, filamentous nonflagellar appendages (Duguid \& Old, 1980) with a diameter of less than $10 \mathrm{~nm}$ and they mediate adhesion (Ottow, 1975). Some strains of $B$. fragilis carry fimbriae (Pruzzo et al., 1984; Shinjo \& Kiyoyama, 1984; van Doorn et al., 1987), but descriptions are not always detailed or apply only to a few strains. Other species of Bacteroides can carry peritrichous fimbriae (Handley \& Tipler, 1986), including $B$. gingivalis which was shown to possess 'curly' fimbriae (Yoshimura et al., 1984). In contrast to fimbriae, some other species of Bacteroides carry fibrils. Fibrils are shorter than fimbriae (usually less than $400 \mathrm{~nm}$ long), with no measurable width and they tend to

Abbreviations: RR, ruthenium red: RRL, ruthenium red staining layer; RBCs, red blood cells. clump to give a tapered appearance (Handley et al., 1985). Fibrils have been described on different species of oral streptococci (Handley et al., 1984, 1985) and have been shown to be responsible for adhesion to epithelial cells and to other bacteria (Weerkamp et al., 1986). Fibrils have also been described on other species of Bacteroides (Handley \& Tipler, 1986; Devine et al., 1989), but not so far on B. fragilis strains.

Several roles have been suggested for the capsule of $B$. fragilis. It has been shown to be important in virulence as capsular material can cause abscesses (Onderdonk et al., 1977) and capsules may be involved in adhesion (Onderdonk et al., 1978) and resistance to phagocytosis (Connolly et al., 1984; Lindberg \& Weintraub, 1985). However, not all strains of $B$. fragilis are capsulate (Brook et al., 1984; Pruzzo et al., 1984) and cultures may contain capsulate and noncapsulate subpopulations (Babb \& Cummins, 1978; Patrick \& Reid, 1983).

Ruthenium red (RR) stains polyanionic polymers with a high charge density (Luft, 1971) and is generally used as a stain for acidic polysaccharides. When used in combination with osmium tetroxide fixation, RR staining has shown that the surface of $B$. fragilis is covered by a RR staining layer (RRL) a thin dense layer external to the outer membrane. The majority of $B$. fragilis strains 
appear to possess a RRL (Kasper et al., 1979), but its role in adhesion and pathogenicity is unclear. It is a separate structure from the capsule seen in Indian ink films (Patrick et al., 1986) and has been implicated as being involved in haemagglutination (Patrick et al., 1988).

High cell surface hydrophobicity correlates with the adhesion of a number of oral organisms to teeth (Weiss et al., 1982) and also with the adhesion of enteropathogenic Escherichia coli to intestinal brush border membranes (Cantey et al., 1981). It is not known whethor hydrophobicity plays an important role in adhesion of $B$. fragilis as most other Bacteroides species are hydrophilic (Handley \& Tipler, 1986).

\section{Methods}

Bacterial strains. Strains ATCC 23745 and NCTC 9343 were obtained from the National Collection of Type Cultures. The remaining seventeen strains were all clinical isolates from abscesses: strain 2/79 was kindly provided by Dr. H. Shah (London Hospital Medical College, UK); strains MRI 2, MRI 3 and MRI 6 to MRI 10 were isolated at the Manchester Royal Infirmary, UK; strains A4, A200, A334, A363, A459, A312, SCI 7, SCI 9 and SCI 13 were kindly provided by Dr D. B. Drucker (Dept of Cell and Structural Biology, University of Manchester, UK).

All strains were identified as B. fragilis using the API 20A kit for the identification of anaerobes.

Media and growth conditions. Cultures were grown in an anaerobic cabinet (Don Whitley mark II) at $37^{\circ} \mathrm{C}$ in an atmosphere of $\mathrm{N}_{2} / \mathrm{H}_{2} / \mathrm{CO}_{2}$ (8:1:1 by vol.) on Columbia agar (Oxoid CM311) supplemented with $5 \%(\mathrm{v} / \mathrm{v})$ horse blood.

All strains were grown in modified brain heart infusion (BHI) broth, $\mathrm{pH} 8$, containing (per litre of distilled water) $: 37 \mathrm{~g} \mathrm{BHI}$ powder (Oxoid CM225), $5 \mathrm{~g}$ yeast extract, I $\mathrm{g} \mathrm{NaHCO}_{3}, 1 \mathrm{~g} \mathrm{KNO}_{3}$ and $500 \mu \mathrm{g}$ menadione. Some strains were also grown in FUM medium which was prepared and sterilized as described by Loesche et al. (1972). FUM, $\mathrm{pH} 7 \cdot 1$, contained (per litre of distilled water): $10 \mathrm{~g}$ tryptone, $5 \mathrm{~g}$ yeast extract, $3 \mathrm{~g}$ glucose, $2 \mathrm{mg}$ haemin, $1 \mathrm{mg}$ menadione, $0.5 \mathrm{~g}$ cysteine

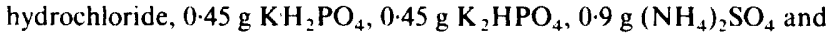
$0.188 \mathrm{~g} \mathrm{MgSO}_{4} .7 \mathrm{H}_{2} \mathrm{O}$.

Negative staining for fimbriae and fibrils. Strains grown for $24 \mathrm{~h}$ in modified $\mathrm{BHI}$ broth were washed three times with water and negatively stained as described by Handley \& Tipler (1986). A drop of bacterial suspension was placed on a grid (400 mesh, Agar Aids) which had been covered with a thin carbon film, or Formvar which had been carboncoated, and plasma-glowed in a Nanotech 300 S coating unit to produce a hydrophilic surface. The bacteria were then negatively stained with a drop of $2 \%(w / v)$ methylamine tungstate (Emscope). Grids were examined under a Hitachi 600 electron microscope and the presence of fimbriae and fibrils was noted. As some staining was not even it was anticipated that there may be some counting error. Therefore four grids prepared from $24 \mathrm{~h}$ cultures of A TCC 23745 were counted to determine the standard deviation for each count.

Negative staining by a spray method. Several spraying methods have been described, some of which have been reviewed by Horne $(1965 a, b)$ and Haschemeyer \& Myers (1972). A spray technique was used to check that the drop method of preparing grids as described above did not select out subpopulations which adhered preferentially to the grid when the excess suspension was blotted off, thus giving abnormally high or low fimbriate counts.
Strain A312 was grown and washed as above and mixed with an equal volume of $1 \%$ methylamine tungstate. $A$ fine aerosol of the suspension was sprayed using an artists' air-brush (DeVilbiss Co.) onto Formvar-coated grids which had been carbon-coated and plasmaglowed. The grids were then allowed to air-dry before being examined under the electron microscope.

Detection of capsules. Capsules were detected by negative staining with Indian ink. A drop of a $24 \mathrm{~h}$ broth culture was mixed on a microscope slide with a drop of $10 \%(w / v)$ glucose and a drop of Indian ink. This was spread thinly over the slide, allowed to air-dry, fixed with ethanol and stained with ammonium crystal violet. Wet preparations were also made by mixing the bacterial suspension, glucose and ink on a slide, placing a coverslip on the mixture and blotting off the excess. The films were examined under a Leitz Dialux 20 light microscope.

Phase variation. The effect of growth phase, incubation temperature and medium on expression of fibrils and fimbriae was investigated. Strains ATCC 23745 (fibrillar) and A312 (fimbriate) were grown in modified BHI broth with samples taken at hourly intervals for negative staining throughout the growth cycle, which was monitored as the $\mathrm{OD}_{660}$. The two strains were also incubated in modified BHI at 20, 37 and $42{ }^{\circ} \mathrm{C}$. Finally, cultures were grown for $24 \mathrm{~h}$ in modified BHI and FUM media. Samples were washed with water and negatively stained with $1 \%$ methylamine tungstate.

Ruthenium red fixation. Acidic polysaccharides were stained using a modification of the method of Luft (1971). Cultures grown for $24 \mathrm{~h}$ in modified BHI were washed three times in $0 \cdot 2 \mathrm{M}$-sodium cacodylate buffer, $\mathrm{pH} \mathrm{7.3.} \mathrm{The} \mathrm{cells} \mathrm{were} \mathrm{then} \mathrm{resuspended} \mathrm{in} \mathrm{equal} \mathrm{volumes} \mathrm{of}$ $3.6 \%(\mathrm{v} / \mathrm{v})$ glutaraldehyde, RR solution $\left(10 \mathrm{mg} \mathrm{m}^{-1}\right)$ (Johnson and Matthey Chemicals) and $0.2 \mathrm{M}$-cacodylate buffer. After $1 \mathrm{~h}$ at room temperature on a turntable, the cells were washed three times in cacodylate buffer and fixed overnight, rotating at room temperature, in a mixture of equal parts of $4 \%(\mathrm{w} / \mathrm{v})$ osmium tetroxide, RR solution and $0.2 \mathrm{M}$-cacodylate buffer. The suspensions were then washed three times in $0.2 \mathrm{M}$-cacodylate buffer. Controls were prepared by substituting distilled water for the RR solution. The cells were then dehydrated in a graded series of ethanol concentrations ( 30 to $100 \%)$ and then embedded in LR White resin (London Resin Co.). After polymerization at $60{ }^{\circ} \mathrm{C}$ for $20 \mathrm{~h}$ sections were cut on a Reichert OMU4 ultramicrotome. Micrographs were taken on a Hitachi 600 electron microscope.

Hexadecane assay. Rosenberg et al. (1980) developed a simple, rapid assay to determine the relative surface hydrophobicity of bacteria by their interaction with hexadecane. The organisms were grown for $24 \mathrm{~h}$ in modified BHI, then washed three times in Sörenson's phosphate buffer, $\mathrm{pH} 7 \cdot 2$. The cells were resuspended in buffer to an $\mathrm{OD}_{440}$ of 0.5 . A sample $(3 \mathrm{ml})$ was transferred to each of six test-tubes. Hexadecane $(200 \mu \mathrm{l})$ was layered on top and the layers mixed by vigorous vortexing for $60 \mathrm{~s}$. The layers were allowed to partition while standing for $15 \mathrm{~min}$. The $\mathrm{OD}_{440}$ of the aqueous phase of six replicates was used to calculate the mean percentage hydrophobicity (Handley et al., 1987). Each strain was assayed twice to monitor variation between batches.

Strain A3/2 was also partitioned and the aqueous layer negatively stained to investigate whether fimbriate cells preferentially adhered to the hexadecane, as fimbriae are often composed of hydrophobic amino acids. The count was compared with that made from the unpartitioned suspension.

Haemagglutination. Chicken, horse, rabbit and human bloods were used to investigate the haemagglutinating activity of the strains. Blood was collected freshly each week and stored at $10 \%(\mathrm{v} / \mathrm{v})$ concentration in Alsever's solution at $4{ }^{\circ} \mathrm{C}$. When needed, blood $(20 \mathrm{ml})$ was washed twice in phosphate-buffered saline (PBS; $8 \mathrm{~g} \mathrm{NaCl} \mathrm{1}^{-1}, 1.21 \mathrm{~g}$ $\left.\mathrm{K}_{2} \mathrm{HPO}_{4} \cdot 3 \mathrm{H}_{2} \mathrm{Ol}^{-1}, 0 \cdot 34 \mathrm{~g} \mathrm{KH}_{2} \mathrm{PO}_{4} \mathrm{1}^{-1}, \mathrm{pH} 7 \cdot 2\right)$ and $0.2 \mathrm{ml}$ of packed 
red blood cells ( $\mathrm{RBCs})$ resuspended to give a $2 \%(\mathrm{v} / \mathrm{v})$ suspension in PBS. Bacterial cultures were grown for $24 \mathrm{~h}$ in modified BHI then washed in PBS, pH 7.4. The cells were resuspended to an $\mathrm{OD}_{600}$ of 1.0 $\left(3 \times 10^{9}\right.$ cells $\left.\mathrm{ml}^{-1}\right)$. The haemagglutination was carried out in roundbottomed microtitre trays. PBS was prepared with $1 \%(w / v)$ BSA to act as a nonspecific protein blocker which prevented the RBCs autoagglutinating, and $50 \mu \mathrm{l}$ of this was placed in each well. An equal volume of bacterial suspension was placed in the first well and double-diluted across the tray. To each well was added $25 \mu \mathrm{l}$ of $2 \% \mathrm{RBCs}$. The tray was shaken for $30 \mathrm{~s}$ at room temperature on a plate shaker and left at room temperature. Trays were examined under a plate microscope for haemagglutination.

\section{Results}

Negative staining for fimbriae and fibrils

Strain ATCC 23745 was the only strain to carry peritrichous fibrils. They were clumped and flexible (Fig. $1 a$ ) and their ends tapered so no width or length was measurable. The fibrils appeared to be repelled from the surface of nonfibrillar cells (Fig. $1 b$ ). In addition, the fibrils seemed to attract each other as they appeared to be attached to fibrils from other cells across spaces between fibrillar cells (Fig. 1c). Fibrils were carried by only $12.3 \%$ of cells from stationary phase broth cultures (Table 1). Four grids were counted to determine the variation introduced by counting error and uneven staining. The standard deviation of the four counts was only \pm 1.4 .

Sixteen strains possessed fimbriae $(2 \cdot 1 \pm 0 \cdot 25 \mathrm{~nm}$ in width). They were flexible structures which appeared to be 'curly' (Fig. 2), were carried on 4 to $41 \%$ of cells in stationary phase culture depending on the strain (Table 1), and their number varied between cells in a population. There was no difference in counts of fimbriate cells of A312 made from grids prepared by the spray method compared with the usual drop method, so there was no preferential adherence of fimbriate cells to the grid to distort the counts.

No structures were found on two (A4 and SCI 13) of the nineteen strains.

\section{Capsule staining}

Only one strain, A334, was noncapsulate. Of the capsulate strains, ATCC 23745, NCTC 9343, SCI 9, SCI 7, A459, A363, A312, A4 and 2/79 all had both capsulate and noncapsulate cells in the same population.

Table 1. Expression of surface structures and surface hydrophobicity of B. fragilis strains

\begin{tabular}{|c|c|c|c|c|}
\hline \multirow[b]{2}{*}{ Strain } & \multicolumn{2}{|c|}{$\begin{array}{l}\text { Percentage of cells } \\
\text { carrying: }\end{array}$} & \multirow{2}{*}{$\begin{array}{c}\text { Hydrophobicity } \\
(\%)\end{array}$} & \multirow{2}{*}{$\begin{array}{l}\text { RRL width } \\
\text { (nm) }\end{array}$} \\
\hline & Fibrils & Fimbriae* & & \\
\hline 23745 & $12 \cdot 3$ & - & $7 \cdot 3(5 \cdot 4)$ & $23 \cdot 9(4-2)$ \\
\hline A459 & - & 41 & $38.0(2.7)$ & $7.9(1.7)$ \\
\hline A312 & - & 35 & $31.5(1.8)$ & $20 \cdot 7(3 \cdot 1)$ \\
\hline MRI 8 & - & 30 & $28.5(1.4)$ & $13.3(2 \cdot 2)$ \\
\hline SCI 7 & - & 20 & $47 \cdot 1(1 \cdot 9)$ & $14.9(3 \cdot 2)$ \\
\hline MRI 2 & - & 19 & $12 \cdot 1(1 \cdot 3)$ & $15 \cdot 3(2.9)$ \\
\hline MRI 10 & - & 16 & $52 \cdot 1(5 \cdot 4)$ & $19 \cdot 5 \cdot(3 \cdot 1)$ \\
\hline $2 / 79$ & - & 14 & $10.9(1.3)$ & $21 \cdot 3(3.9)$ \\
\hline MRI 9 & - & 11 & $9.8(2.5)$ & $21.8(4 \cdot 2)$ \\
\hline MRI 7 & - & 11 & $17.4(1.4)$ & $19 \cdot 3(2 \cdot 1)$ \\
\hline A363 & - & 10 & $14.8(5.7)$ & $11.6(2.2)$ \\
\hline MRI 3 & - & 10 & $9.2(1.0)$ & $13 \cdot 1(1.9)$ \\
\hline SCI 9 & - & 8 & $13.1(1.4)$ & $15.4(1.9)$ \\
\hline 9343 & - & 7 & $16.6(3.1)$ & $20 \cdot 7(4 \cdot 3)$ \\
\hline A200 & - & 7 & $6 \cdot 6(2 \cdot 7)$ & $15 \cdot 0 \cdot(2 \cdot 2)$ \\
\hline MRI 6 & - & 6 & $8.2(0.7)$ & $14.9(1.6)$ \\
\hline A334 & - & 4 & $51.9(1.8)$ & $18 \cdot 1(4 \cdot 5)$ \\
\hline A4 & - & - & $10.7(2.6)$ & $14 \cdot 1(3 \cdot 2)$ \\
\hline SCI 13 & - & - & $25 \cdot 1(3 \cdot 1)$ & $19.5(2.9)$ \\
\hline
\end{tabular}

* Counts on 100 cells were made from a 24 hour broth culture, negatively stained.

$\dagger$ Hydrophobicity values calculated are means (SD values in parentheses) from six replicates from two separate batches of cells.

$\ddagger$ Values represent the mean thickness (SD values in parentheses) of the RRL on ten different cells. 

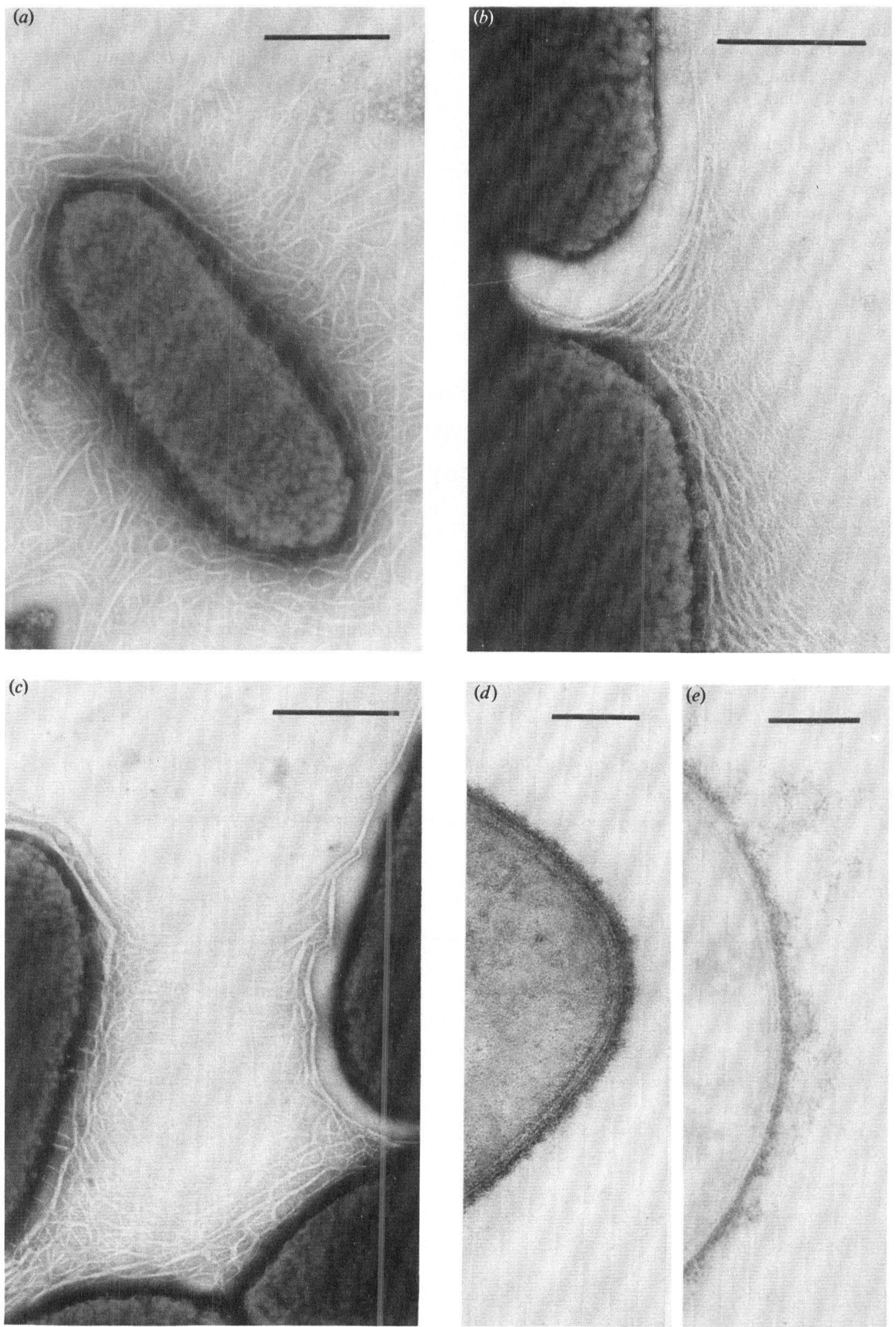

Fig. 1. Laboratory strain ATCC 23745 negatively stained with $1 \%$ methylamine tungstate. (a) Clumped fibrils forming a matrix around the cell. Bar, $0.5 \mu \mathrm{m}$. (b) Zones around nonfibrillar cells were often seen which may have been due to a repulsion between fibrils and the cell surface. Bar, $0.5 \mu \mathrm{m}$. (c) Fibrils fused across spaces between cells. Bar, $0.5 \mu \mathrm{m}$. (d) Staining of ATCC 23745 with RR revealed the RRL of width $23.86 \pm 4.24 \mathrm{~nm}$. Fibrils did not stain. Bar, $0 \cdot 1 \mu \mathrm{m}$. (e) Strain A363 stained with RR revealed the RRL with loose amorphous material coming off the cell surface. Bar, $0 \cdot 1 \mu \mathrm{m}$. 


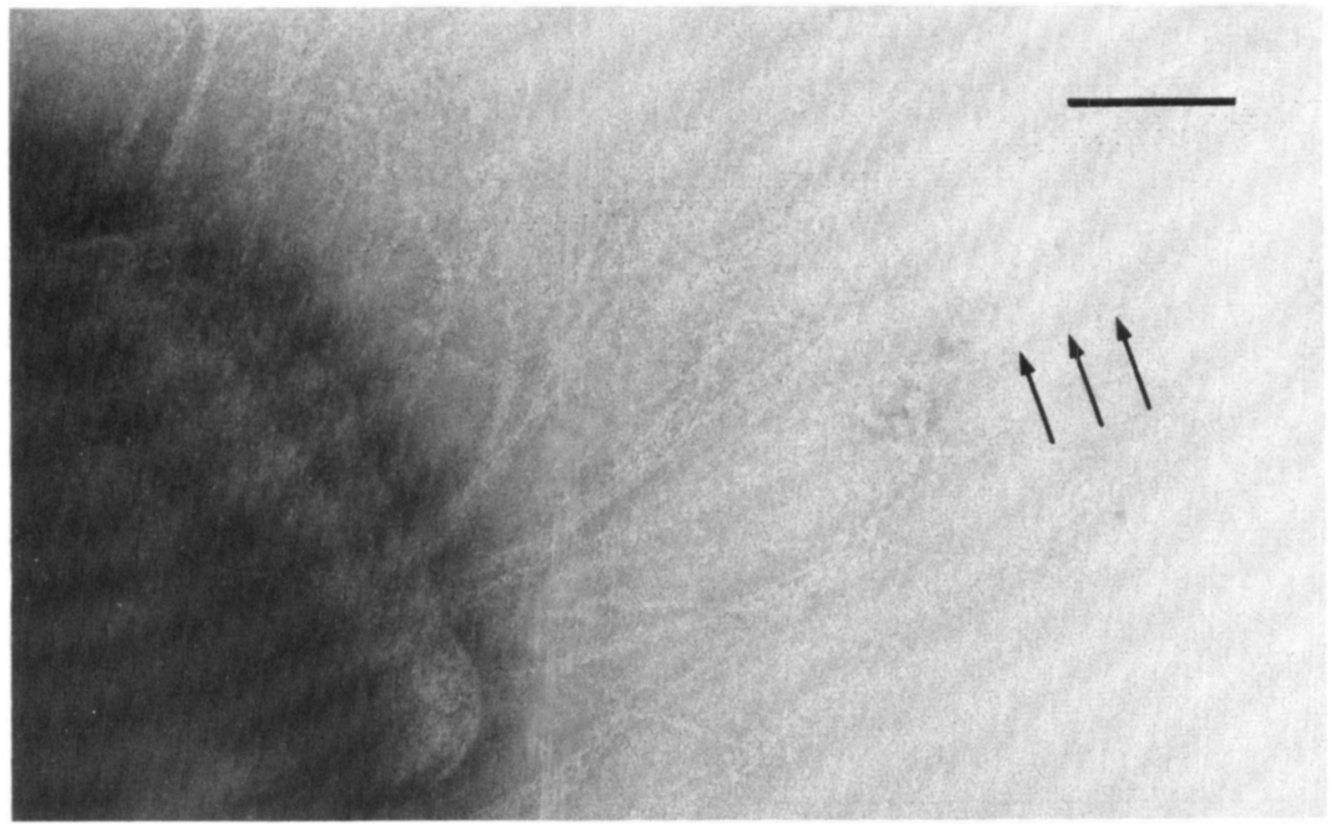

Fig. 2. B. fragilis A312 negatively stained with methylamine tungstate, showing the 'curly' appearance of the fimbriae (arrowed). Fimbriae appeared to clump at the base and spread at the ends to show the individual thin structures. Bar, $0 \cdot 1 \mu \mathrm{m}$.

The largest capsules were seen on strain ATCC 23745, although this strain and strains A363, A312, A4, NCTC 9343, MRI 7 and MRI 9 showed a range of capsule sizes. The proportion (over $90 \%$ ) of capsulate cells of ATCC 23745 did not vary with growth phase.

\section{Phase variation}

Fibril expression on $B$. fragilis ATCC 23745 did not vary significantly with growth phase, incubation temperature or medium. However, the expression of fimbriae by strain A312 did show phase variation, decreasing from $35 \%$ of cells in the inoculum to almost zero in early exponential phase, and increasing again to $34 \%$ in late exponential phase. Expression of fimbriae was also completely repressed at all stages of growth by incubation at $20^{\circ} \mathrm{C}$. In contrast, fimbrial expression was not affected by incubation at $42^{\circ} \mathrm{C}$. When cells were examined after growth in FUM or BHI, no variation in expression was observed between the two types of broth culture.

\section{Ruthenium red fixation}

All strains carried an amorphous electron dense RRL adjacent to the outer membrane (Fig. $1 d$ ). The width of this layer ranged from $7.9 \pm 1.7 \mathrm{~nm}$ on strain A459 to $23.9 \pm 4 \cdot 2 \mathrm{~nm}$ on ATCC 23745 (Table 1). Fimbriae, fibrils or capsules were not observed after RR staining, although some cells did show loosely attached fragments of RR staining material close to the RRL (Fig. 1e). No structure equivalent to the RRL was seen in the nonstained control sections.

\section{Cell surface hydrophobicity}

The most hydrophobic strain was MRI $10(52 \cdot 1 \%)$, and the most hydrophilic was strain A200 (6.6\%) (Table 1). The remaining strains fell into a range between these values and no clear groupings were visible.

When the bacteria in the aqueous phase were negatively stained after partitioning of $\mathrm{A} 312$, there was no difference in the proportion of fimbriate cells when compared to the original unassayed suspension. Therefore fimbriate bacteria were not being preferentially partitioned with the hexadecane layer.

\section{Haemagglutination}

Only one strain of $B$. fragilis (A459) was able to strongly haemagglutinate, and it agglutinated all four blood types tested. No other strain agglutinated horse or human RBCs. All strains except NCTC 9343, A4, SCI 9, 2/79, MRI 3, MRI 8 and MRI 9 were able to haemagglutinate rabbit blood (Table 2), although most strains were only able to haemagglutinate weakly at bacterial concentra- 
Table 2. Haemagglutination by strains of $B$. fragilis

+++++ , Haemagglutination at $9.37 \times 10^{7}$ bacteria $\mathrm{ml}^{-1} ;++++$, at

$1.87 \times 10^{8} \mathrm{ml}^{-1} ;+++$, at $3.75 \times 10^{8} \mathrm{ml}^{-1} ;++$, at $7.5 \times 10^{8} \mathrm{ml}^{-1} ;+$, at $1.5 \times 10^{9} \cdot \mathrm{ml}^{-1}$.

\begin{tabular}{|c|c|c|c|c|c|}
\hline \multirow[b]{2}{*}{ Strain } & \multirow[b]{2}{*}{$\begin{array}{l}\text { Structure } \\
\text { type* }\end{array}$} & \multicolumn{4}{|c|}{ Haemagglutination of RBGs from: } \\
\hline & & Chicken & Rabbit & Horse & $\begin{array}{c}\text { Human } \\
\text { group O }\end{array}$ \\
\hline 23745 & Fib & + & + & - & - \\
\hline A459 & $\mathrm{F}$ & $+++t$ & $++t+$ & +++ & ++++ \\
\hline A 312 & $\mathbf{F}$ & - & + & - & - \\
\hline MRI 8 & $\mathrm{~F}$ & - & - & - & - \\
\hline $\mathrm{SCI} 7$ & $\mathrm{~F}$ & - & + & - & - \\
\hline MRI 2 & $\mathrm{~F}$ & - & +++ & - & - \\
\hline MRI 10 & $\mathrm{~F}$ & + & + & - & - \\
\hline $2 / 79$ & $\mathbf{F}$ & - & - & - & - \\
\hline MRI 9 & $\mathrm{~F}$ & - & - & - & - \\
\hline MRI 7 & $\mathrm{~F}$ & - & + & - & - \\
\hline A363 & $\mathbf{F}$ & + & - & - & - \\
\hline MRI 3 & $\mathbf{F}$ & - & - & - & - \\
\hline SCI 9 & $\mathbf{F}$ & - & - & - & - \\
\hline 9343 & $F$ & - & - & - & - \\
\hline A200 & $F$ & - & ++ & - & - \\
\hline MRI 6 & $F$ & - & + & - & - \\
\hline A 334 & $\mathbf{F}$ & - & + & - & - \\
\hline A4 & B & - & - & - & - \\
\hline SCI 13 & B & - & + & - & - \\
\hline
\end{tabular}

* F, fimbriate strain; Fib, fibrillar strain; B, bold strain.

tions of $1.5 \times 10^{9}$ bacteria $\mathrm{ml}^{-1}$. For strain A459, chicken blood was the most positive, being agglutinated at a bacterial concentration of $9.37 \times 10^{7}$ bacteria $\mathrm{ml}^{-1}$. Thus there was no correlation between surface structure expression, cell surface hydrophobicity and the ability to haemagglutinate.

\section{Discussion}

This study has shown that $B$. fragilis consists of three structural subgroups, as strains were found to carry fimbriae, fibrils or no surface structures.

Fibrils have not previously been reported on B. fragilis, but have been found on other Bacteroides species (Handiey \& Tipler, 1986; Weiss et al., 1988; Devine et al., 1989). Fibrils were found only on strain ATCC 23745, and appear to be atypical for $B$. fragilis. The majority of the strains possessed fimbriae with a mean diameter of $2.1 \mathrm{~nm}$, which fall into the 'very thin' category proposed by Paranchych \& Frost (1988).

The fimbriae observed in this study appeared in some preparations to be 'curly', the term used by Yoshimura $e t$ $a l$. (1984) to describe the fimbriae of $B$. gingivalis 381 . However, further high resolution electron microscopy studies are necessary to clarify their ultrastructure in detail. Thin curly fimbriae are not restricted to Bacteroides. They have also been observed on Haemophilus influenzae (van Alphen et al., 1988) and the K99 adhesin of $E$. coli was described as having an 'open helical' structure (Jacobs \& de Graaf, 1985).

Fibril expression by B. fragilis ATCC 23745 was not subject to phase variation, but fimbrial expression by A312 showed repression at $20^{\circ} \mathrm{C}$ and in early exponential phase. This supports work by van Doorne et al. (1987), who showed by Western blotting that the expression of $B$. fragilis fimbriae was repressed at $20^{\circ} \mathrm{C}$. However, even at maximum expression the majority of $B$. fragilis cells were nonfimbriate.

Strain ATCC 23745 has a range of capsule sizes, and both capsulate and noncapsulate cells are present in a population (Patrick et al., 1986); this was seen with the capsulate strains studied here. Only $12.3 \%$ of ATCC 23745 cells carried fibrils whereas $90 \%$ of cells carried capsules, so capsules and fibrils represent distinct cell surface polymers and fibrils are not artefacts representing the collapsed capsule.

The RRL has previously been called the capsule by Kasper (1976) and Kasper et al. (1980). However, the noncapsulate $B$. fragilis strain A334, which showed no halo by the Indian ink method, possessed a RRL. Therefore the two techniques are not detecting the same 
structure and the term capsule should be reserved only for the halo seen by light microscopy. All strains in this study had a RRL which was carried by all cells within a population even when a subpopulation was noncapsulate. The function of the RRL is not known, although its thickness may be able to influence the level of cell surface hydrophobicity (Harty \& Handley, 1989), but no such correlation was observed in this study.

Although RR did not preserve the capsules of $B$. fragilis strains in this study, Patrick et al. (1986) did detect a RR staining matrix on ATCC 23745 and NCTC 9343 which they suggested was the capsule. RR has also been shown to stain the glycoprotein fibrils of $S$. salivarius (Handley et al., 1988), but fibrils of B. fragilis ATCC 23745 were found not to stain with RR in this study.

The $B$. fragilis strains studied here showed fairly low cell surface hydrophobicity values. Capsules are usually hydrophilic and may therefore contribute to the low hydrophobicity of these strains. It has been proposed that hydrophobic properties may be carried on some types of fimbriae (Boedeker et al., 1979; Honda et al., 1984; Sherman et al., 1985), but there was no correlation between surface structure type and hydrophobicity for these strains. Even for fimbriate and fibrillar strains, the majority of cells in a population did not carry surface structures, and therefore the effect of fibrils and fimbriae on cell surface hydrophobicity is likely to be limited.

Several previous papers have discussed the ability of $B$. fragilis to agglutinate RBCs. Haemagglutination by $B$. fragilis has been proposed to be a property of the capsule (Riley \& Mee, 1984), electron dense layer (Patrick et al., 1988) and fimbriae (Pruzzo et al., 1984). This study, in common with the work published by Vel et al. (1986), Shinjo \& Kiyoyama (1984) and Pruzzo et al. (1989), found no correlation between surface structures and the ability to agglutinate RBCs. From all the conflicting data listed above it may be possible that more than one adhesin may be involved or that an outer membrane protein may be responsible for haemagglutination.

\section{References}

VAN Alphen, L., VAN DEN BERghe, N. \& VAN DEN BROEK, L. G. (1988) Interaction of Haemophilus influenzae with human erythrocytes and oropharyngeal epithelial cells is mediated by a common fimbrial epitope. Infection and Immunity 56, 1800-1806.

BABB, J. L. \& Cummins, C. S. (1978). Encapsulation of Bacteroides species. Infection and Immunity 19, 1088-1091.

Boedeker, E. C., Cheney, P. A., Schad, P. A. \& Formal, S. B. (1979) Hydrophobic bacterial properties correlates with the adherence of enteropathogens to intestinal brush border membranes (BBM). Gastroenterology 76, 1105.

Brook, I., Coolbaugh, J. L. \& Walker, R. I. (1984). Pathogenicity of piliated and encapsulated Bacteroides fragilis. European Journal of Clinical Microbiology 3, 207-209.
Cantey, J. R., Luslibaugh, W. S. \& Inman, L. R. (1981). Attachment of bacteria to intestinal epithelial cells in diarrhoea caused by $E$. col $\mathrm{RDE} \mathrm{Cl}$ in the rabbit: stages and role of capsule. Journal of Infectious Disease 143, 219-230.

Connolly, J. C., McClean, C. \& Tabaqchili, S. (1984). The effect of capsular polysaccharide and lipopolysaccharide of Bacteroides fragilis on polymorph function and serum killing. Journal of Medical Microbiology 17, 259-271.

Devine, D. A., GmüR, R. \& HANDLey, P. S. (1989). Ultrastructure, serogrouping and localization of surface antigens of Bacteroides intermedius. Journal of General Microbiology 135, 967-997.

VAN DOORN, J., MoOI, F. R., Verweij-VAN Vught, A. \& MaCClaren, D. M. (1987). Characterization of fimbriae from Bacteroides fragilis. Microbial Pathogenesis 3, 87-95.

Duguid, J. P. \& OLD, D. C. (1980). Adhesive properties of Enterobacteriaceae. In Bacterial Adherence Series Receptors and Recognition, vol. 6, series B, pp. 187-215. Edited by E. H. Beachey. London: Chapman and Hall.

HANDley, P. S. \& TiPleR, L. S. (1986). An electron microscope survey of the surface structures and hydrophobicity of oral and non-oral species of the bacterial genus Bacteroides. Archives of Oral Biology 31 325-335.

Handley, P. S., Carter, P. L. \& Fielding, J. (1984). Streptococcus salivarius strains carry either fibrils or fimbriae on the cell surface. Journal of Bacteriology 157, 64-72.

Handley, P. S., Carter, P. L., Wyatt, J. E. \& Hesketh, L. M. (1985). Surface structures (peritrichous fibrils and tufts of fibrils) found on Streptococcus sanguis strains may be related to their ability to coaggregate with other oral genera. Infection and Immunity 47, 217 227.

Handley, P. S., Harty, D. W. S., Wyatt, J. E., Brown, C. R., Doran, J. P. \& GibBs, A. C. C. (1987). A comparison of the adhesion, coaggregation and cell surface hydrophobic properties of fibrillar and fimbriate strains of Streptococcus salivarius. Journal of General Microbiology 133, 3207-3217.

Handley, P. S., Hargreaves, J. \& Harty, D. W. S. (1988) Ruthenium red staining reveals surface fibrils and a layer external to the cell wall in Streptococcus salivarius $\mathrm{HB}$ and adhesion deficient mutants. Journal of General Microbiology 134, 3165-3172.

HARTY, D. W. S. \& HANDLEy, P. S. (1989). Expression of the surface properties of the fibrillar Streptococcus salivarius HB and its adhesion deficient mutants grown in continuous culture under glucose limitation. Journal of General Microbiology 135, $2611-2621$.

HASCHEMEYER, R. H. \& MYERS, R. J. (1972). Negative staining. In Principles and Techniques of Electron Microscopy, Biological Applications, vol. 2, pp. 101-147. Edited by M. A. Hayat. New York: Van Nostrand Reinhold.

Honda, T., ARITA, M. \& Miwatani, T. (1984). Characterization of new hydrophobic pili of the enterotoxigenic Escherichia coli: a possible new colonization factor. Infection and Immunity 43, 959-965.

HORNE, R. W. (1965a). The examination of small particles. In Techniques for Electron Microscopy, 2nd edn, pp. 311-327. Edited by D. H. Kay. Oxford: Blackwell Scientific Publications.

HORNE, R. W. (1965b). Negative staining methods. In Techniques for Electron Microscopy, 2nd edn, pp. 328-355. Edited by D. H. Kay. Oxford: Blackwell Scientific Publications.

Jacobs, A. A. C. \& DE GraAF, F. K. (1985). Production of K88, K99 and $\mathrm{F} 41$ fibrillae in relation to growth phase, and a rapid procedure for adhesin purification. FEMS Microbiology Letters 26, 15-19.

KASPER, D. L. (1976). The polysaccharide capsule of Bacteroides fragilis subspecies fragilis: immunochemical and morphologic detection. Journal of Infectious Diseases 133, 79-87.

Kasper, D. L., Onderdonk, A. B., Polk, B. F. \& Bartlett, J. G. (1979). Surface factors as virulence factors in infection with Bacteroides fragilis. Reviews of Infectious Diseases 1, 278-288.

Kasper, D. L., ONderdonk, A. B., Reinap, B. G. \& LindberG, A. A. (1980). Variations of Bacteroides fragilis with in vitro passage: presence of an outer membrane-associated glycan and loss of capsular antigen. Journal of Infectious Diseases 142, 750-756.

LindBerG, A. A. \& Weintraub, A. B. (1985). Encapsulation and protection against phagocytosis by Bacteroides fragilis. Scandinavian Journal of Infectious Diseases 46, 27-32. 
Lindberg, A. A., Berthold, P., Nord, C. \& Weintraub, A. (1979). Encapsulated strains of Bacteroides fragilis in clinical specimens. Medical Microbiology and Immunology 167, 29-36.

Loesche, W. J., HocketT, R. N. \& Syed, S. A. (1972). The predominant cultivable flora of tooth surface plaque removed from institutionalized subjects. Archives of Oral Biology 17, 1311-1325.

LufT, J. H. (1971). Ruthenium Red and Ruthenium Violet. I. Chemistry, purification, methods of use for electron microscopy and mechanisms of action. Anatomical Record 171, 347-368.

Onderdonk, A. B., Kasper, R. L., Cisneros, R. L. \& Bartlett, J. G. (1977). The capsular polysaccharide of Bacteroides fragilis as a virulence factor: comparison of the pathogenic potential of encapsulated and unencapsulated strains. Journal of Infectious Diseases 136, 82-89.

Onderdonk, A. B., Moon, N. E., Kasper, D. L. \& Bartlett, J. G. (1978). Adherence of Bacteroides fragilis in vivo. Infection and Immunity 19, 1083-1087.

Otrow, J. (1975). Ecology, physiology and genetics of fimbriae and pili. Annual Review of Microbiology 29, 79-108.

Paranchych, W. \& Frost, L. S. (1988). The physiology and biochemistry of pili. Advances in Microbial Physiology 29, 53-114.

Patrick, S. \& REID, J. H. (1983). Separation of capsulate and noncapsulate Bacteroides fragilis on a discontinuous density gradient. Journal of Medical Microbiology 16, 239-241.

Patrick, S., Reid, J. H. \& CofFey, A. (1986). Capsulation of in vitro and in vivo grown Bacteroides species. Journal of General Microbiology 132, 1099-1109.

Patrick, S., Coffey, A., Emmerson, A. M. \& Larkin, M. J. (1988). The relationship between cell surface structure expression and haemagglutination in Bacteroides fragilis. FEMS Microbiology Letters 50, 67-71.

Pruzzo, C., Dainelli, B. \& Richetti, M. (1984). Piliated Bacteroides fragilis strains adhere to epithelial cells and are more sensitive to phagocytosis by human neutrophils than non-piliated strains. Infection and Immunity 43, 189-194.

Pruzzo, C., Guzman, C. A. \& Dainelli, B. (1989). Incidence of haemagglutination activity among pathogenic and nonpathogenic Bacteroides fragilis strains and role of capsule and pili in $\mathrm{HA}$ and adherence. FEMS Microbiology Letters 59, 113-118.

RILEY, T. V. \& MEE, B. J. (1984). Haemagglutination of Bacteroides fragilis. FEMS Microbiology Letters 25, 229-232.

Rosenberg, M., GUTNICK, D. \& Rosenberg, E. (1980). Adherence of bacteria to hydrocarbons: a simple method for measuring cellsurface hydrophobicity. FEMS Microbiology Letters 9, 29-33.

Sherman, P. M., Houston, W. L. \& Boedeker, E. C. (1985). Functional heterogeneity of intestinal $E$. coli strains expressing type 1 somatic pili (fimbriae): assessment of bacterial adherence to intestinal membranes and surface hydrophobicity. Infection and Immunity 49, 797-804.

Shinjo, T. \& Kiyoyama, H. (1984). Fimbriae and haemagglutination in the Bacteroides fragilis group. Japanese Journal of Veterinary Science 46, 373-375.

Vel, W. A. C., Namavar, F., Marian, A., Verweij-Van Vught, J. J., Pubben, A. B. \& MacLaren, D. M. (1986). Haemagglutination by the Bacteroides fragilis group. Journal of Medical Microbiology 21, 105-107.

Weerkamp, A. H., Handley, P. S., BaARs, A. \& Slot, J. W. (1986). Negative-staining and immunoelectron microscopy of adhesiondeficient mutants of Streptococcus salivarius reveal that the adhesive protein antigens are separate classes of cell surface fibril. Journal of Bacteriology 165, 746-755.

Weiss, E., Rosenberg, M., Judes, H. \& Rosenberg, E. (1982). Cell surface hydrophobicity of adherent oral bacteria. Current Microbiology 7, 125-128.

Weiss, E. I., London, J., Kolenbrander, P. E., Hand, A. R. \& SIRAGANIAN, R. (1988). Localization and enumeration of fimbriaassociated adhesins of Bacteroides loeschii. Journal of Bacteriology 170, 1123-1128

Yoshimura, F., Takahashi, K., Nodasaka, Y. \& Suzuki, T. (1984). Purification and characterization of a novel type of fimbriae from the oral anaerobe Bacteroides gingivalis. Journal of Bacteriology 160, 949-957. 